Document downloaded from:

http://hdl.handle.net/10251/64911

This paper must be cited as:

Pellicer, E.; Sanz Benlloch, MA.; Esmaeili, B.; Molenaar, KR. (2016). Exploration of Team Integration in Spanish Multifamily Residential Building Construction. Journal of Management in Engineering. 32:05016012-1-05016012-11. doi:10.1061/(ASCE)ME.1943-5479.0000438.

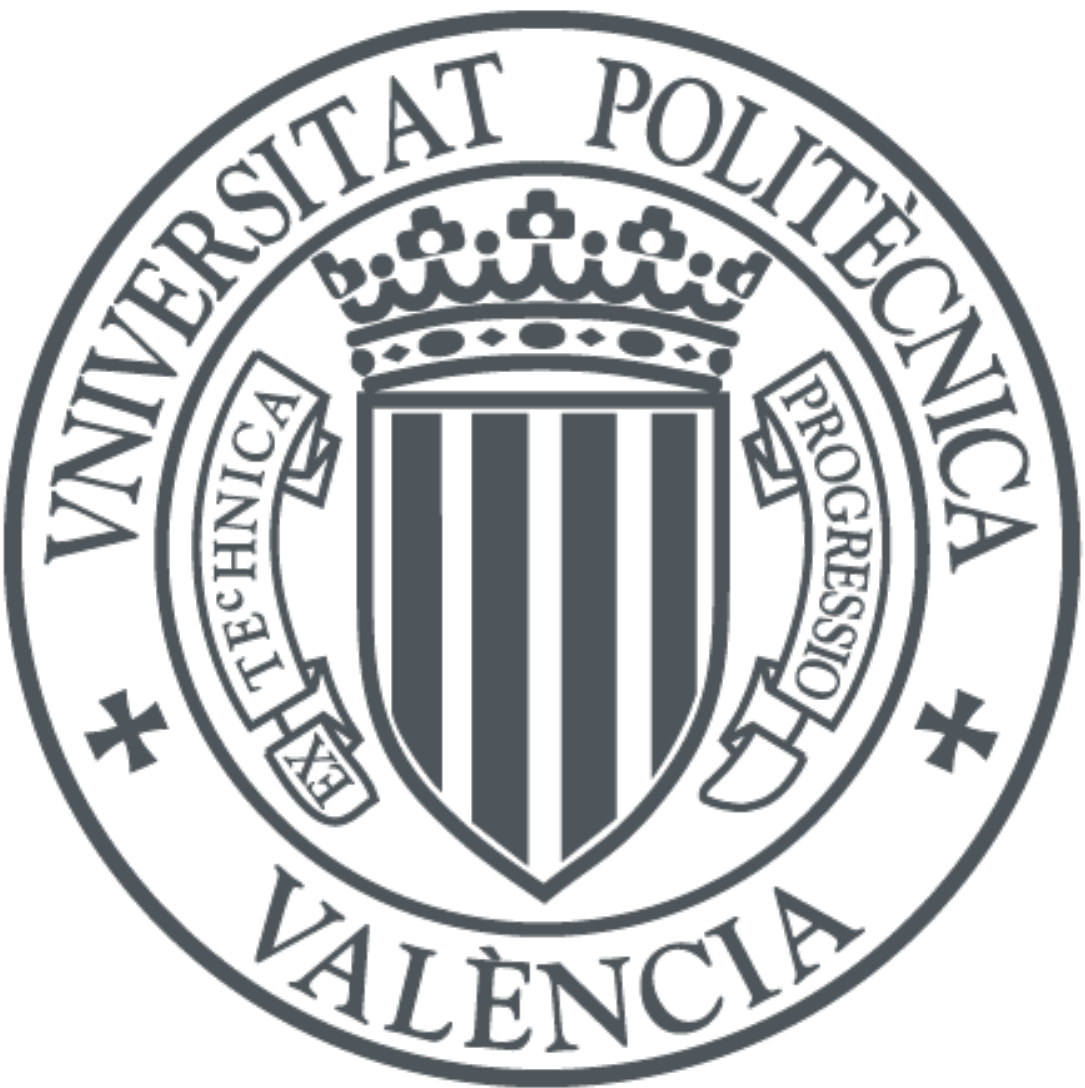

The final publication is available at

http://dx.doi.org/10.1061/(ASCE)ME.1943-5479.0000438

Copyright American Society of Civil Engineers

Additional Information 


\section{EXPLORATION OF TEAM INTEGRATION IN SPANISH MULTI-FAMILY RESIDENTIAL BUILDING}

\section{CONSTRUCTION}

\author{
Eugenio Pellicer ${ }^{1 *}$, M. Amalia Sanz ${ }^{2}$, Behzad Esmaeili ${ }^{3}$, and Keith R. Molenaar ${ }^{4}$
}

\section{ABSTRACT}

Project delivery team integration generally involves early involvement of general contractors and key specialty contractors in the design process. Team integration has been found to improve an owner's probability of success. However, during difficult economic times, owners can forego early team involvement and move towards low bid procurement to take advantage of competitive markets. This study explores the performance of integrated teams in the Spanish multifamily building construction market in light of the 2007 financial crisis. After conducting structured interviews of 31 residential building projects with the owner and main contractor of each one of them, this study identified eight projects for in-depth case studies. These eight case studies represented the best performing, worst performing and atypical cases. The results show that Spanish building owners experience higher success by developing integrated teams. This integration begins with how the owner organizes the team for success (i.e., integrated builder services, qualifications-based procurement and prior experience) and promotes integration throughout the project process (i.e., timeliness of communications, shared commitment to goals and development of team chemistry).

\footnotetext{
${ }^{1}$ Associate Professor, School of Civil Engineering, Universitat Politècnica de València, Camino de Vera s/n, 46022 Valencia, Spain, pellicer@upv.es.

* Corresponding Author: tel. +34.963.879.562; fax +34.963.877.569.

2 Instructor, School of Civil Engineering, Universitat Politècnica de València, Camino de Vera s/n, 46022 Valencia, Spain, asanz@cst.upv.es.

${ }^{3}$ Assistant Professor, University of Nebraska at Lincoln, School of Architectural Engineering and Construction, Omaha Campus, 1110 S. 67th Street, Omaha, NE 68182-0681, besmaeili2@unl.edu.

${ }^{4}$ Professor, University of Colorado at Boulder, Dept. of Civil, Environmental and Architectural Engineering, UCB 428, Boulder, CO 80309-0428, keith.molenaar@colorado.edu.
} 
KEYWORDS: Building Residential, Integration, Owner, Spain, Success

\section{INTRODUCTION}

Problem Statement

The topic of project team integration has been studied internationally as a means to improve project success (Nam and Tatum 1992; Latham 1994). Project team integration, through more interaction and collaboration early in the design process, has led to success in mitigating industry fragmentation on a project-by-project basis (El Asmar et al. 2013; Konchar and Sanvido 1998). Along these lines, Pocock et al. (1996) acknowledged that projects with low degree of interaction had a wide range of cost and schedule growth and number of modifications, while projects with high degree of interaction tended to have better and more consistent performance indicators. Konchar and Sanvido (1998) concluded that more integrated delivery methods (design-build, construction manager at risk, and design-bid-build in descending order of integration) provided better results in terms of cost and schedule. They also found that design-build projects performed equal to, or better than, the other less integrated delivery methods.

While these results are promising, there are gaps in knowledge about project integration and performance. For example, within the construction industry, the building of multi-family residential housing has always been the biggest piece of the market; i.e., it comprises at least forty percent of new construction in both the United States and Spain (Department of Commerce 2015; SEOPAN 2014). This market is characterized by private owners

42 who have to comply with construction standards and zoning regulations basically, but have the latitude to form teams that can meet the customers' desires. Civil engineering works, on the other hand, are mainly developed by public agencies that have to follow strict procedures and 
market is composed of industrial and commercial buildings in which, most of the time, the

47 investment is very large and the design and construction show wider ranges of typology and complexity (Knutson et al. 2008). Therefore, the building residential sub-sector seems a promising target in order to analyze project team integration, due to the fact that owners have enough flexibility in their team configuration and development, there is a large enough sample of fairly homogeneous projects and, in general, owners are more willing to cooperate because they do not fear public exposure, such as in civil engineering infrastructures and in large industrial and commercial facilities (Flyvbjerg 2007). Little research exists to define project team integration in this setting and determine how it impacts project success.

\section{Context of Inquiry}

57 This research is focused on the Spanish building residential sub-sector. Within this context, the design and construction market is fundamentally limited to design-bid-build project delivery (Pellicer and Victory 2006; Pellicer et al. 2014). In Spain, the building of residential housing has always been the biggest piece of the market: $43 \%$ out of the total new facilities built, a figure very similar to the one from the U.S. (Department of Commerce 2015), and 647,000 new homes built in 2007 (developed from SEOPAN 2014).

The financial crisis of 2007 affected the construction sector deeply, mainly in the European Mediterranean countries; this crisis was especially intense in Spain because of the real estate bubble (Carballo-Cruz 2011). Comparing data from the beginning of the crisis in 2007 to the peak of the crisis in 2013 , there was a reduction of $82 \%$ in public procurement, $94 \%$

67 in new building production, and $89 \%$ in isolated single-housing (CNC 2014). Furthermore, from 2008 to $2013,33 \%$ of the companies working in the construction industry were forced into bankruptcy (CNC 2014). 
71 the best can stay in business (Oviedo-Haito et al. 2014). During difficult economic times, owners

72 frequently move towards low bid construction procurement to take advantage of competitive

73 markets. Some multi-family housing developers have looked to low prices in the market to

74 sustain business while others have employed integrated construction teams as a strategy. The

75 multi-family housing market provides an excellent laboratory to explore the impacts of integration on Spanish building construction.

\section{Goal of the Research}

Given the gaps in understanding of how integration impacts performance combined with the opportunity to study the Spanish building market in this unprecedented time of change, the objective of this research is to explore the effect of integration on performance in the Spanish multi-family housing design and construction sector. Baiden and Price (2011, p.129) define team integration as "where different disciplines or organizations with different needs and cultures merge into a single cohesive and mutually supporting unit." This paper will more specifically define integration for the Spanish residential building sector. The next section presents a literature review on performance measures as they relate to project delivery

87 characteristics and integration. A thorough explanation of the research method follows. The approach involved a survey of 31 Spanish building projects (i.e., the building being the unit of analysis); the responses for each project were obtained from the owners and main contractors, all of them using structured interviews. The results were analyzed with a principal component analysis (PCA) to understand and categorize the level of integration on the projects. With this understanding, eight in-depth case studies were conducted, representing the best and worst performing projects for both integrated and non-integrated projects, to derive the conclusions.

94 The research conclusions provide a characterization of integration in the Spanish residential 
concludes with a discussion of how these results relate to the body of knowledge in design and construction integration and how the findings may be generalized outside of the Spanish multifamily residential building market.

\section{MEASURING PROJECT SUCCESS}

As the methodology section of this paper explains, the research involves an examination of input variables, decision variables and outcome variables to determine the impacts of integration. A thorough literature review was used to identify more than 250 potential variables. The research team used a structured workshop or "research charrette" to prioritize the list of variables. The research charrette provides for multiple industry experts to interact in a structured manner (Gibson and Whittington 2009). A two-day charrette workshop was held with the authors and a panel of industry professionals, which included two general contractors, two specialty contractors, three owners, two lawyers and one architect. All attendees had at least 15 years of experience in the construction industry. Beginning with the end in mind, the outcome variables are explained first. Outcome variables define project success such as time and cost; the literature is rich in this area. Decision variables, which are those variables that define project team integration such as timing of builder involvement and procurement methods, are explained next. Again, the literature is rich in this area. Input variables are explained last. These are simply the project characteristics such as building type and size. This section explains each of these variables in order to describe how success and integration are measured in this study.

\section{Outcome Variables}

The literature is deep in the exploration of variables that define design and construction project performance. These are often referred to as success factors. Definitions vary based upon the 
121

122

123

124

125

126

127

128

129

130

131

132

133

134

135

136

137

138

139

140

141

142

143

144

145

scenario that the researchers are analyzing and the perspectives of the stakeholders. For example, owners often look for a certain level of quality as the main driver when they will own a facility throughout its lifespan. They will also look closely at meeting a schedule if the project is revenue generating or if it has definitive occupancy needs. Contractors are also concerned with quality and schedule, but cost is usually the main factor that defines project success from their business perspective. Table 1 summarizes 15 of the most relevant contributions to this topic. The qualitative and quantitative measures refer to performance measures and project success. It draws attention to the fact that the 12 of the 15 studies use both quantitative and qualitative measures of success. All studies use some form of quantitative measures, generally through project cost and schedule growth. Fewer use qualitative measures, but those that do tend to apply these measures to project quality and/or general user satisfaction with the project.

<Insert Table 1 here>

\section{Decision Variables}

The decision variables are those that help us to explain the outcome variables in relation to the focus of the study, which is project integration. Project integration is directly discussed in the literature. It is also indirectly discussed through topics such as project delivery method, procurement procedures, team characteristics, and team integration.

The four primary delivery methods, in ascending order of integration, are: design-bidbuild, construction management at risk, design-build, and integrated project delivery. It is worth saying that sometimes the boundaries between them can be ambiguous. The design-bidbuild project delivery method is the most used method worldwide; it is commonly named the traditional method of project delivery. The owner grants the design to an architect or engineer (generally an architectural firm and consulting engineering). When the design is completed in 
detail and approved by the owner, the project is bid to a constructor; in this approach the contractor has no input during the design phase. Construction management at risk begins to provide more integration by including the constructor in the design phase (Konchar and Sanvido 1997). The owner still has separate contracts with the designer and constructor; the contract with the constructor contains two parts: (1) preconstruction services, and (2) construction. Design-build uses a single entity to delivery both design and construction (Beard et al. 2001; Molenaar et al. 1999); the single contract between the owner and design-builder, which is generally signed based on a basic design, inherently requires integration within the design-build entity. Integrated project delivery is an emerging approach to promote more integration and collaboration among the owner, designer and constructor (El Asmar et al. 2013). One multiparty contract is signed by all core team members. The basis of this contract is a relationship of trust between the contractual parties (Ballard and Howell 2003; El Asmar et al. 2013). Some authors (Kumaraswamy et al., 2005; Rahman and Kumaraswamy 2008) indicated that cooperative team-working is improved by moving from classical to relational contracting; the main barrier to collaborative team-working is mainly the lack of trust. According to these authors there are four factors that encourage cooperative team-working: owner's competencies, prior interactions, compatible organizational culture, and better selection of project partners.

In the Spanish construction industry, the most popular delivery method among public agencies is the traditional design-bid-build (de la Cruz et al. 2006; SEOPAN 2014). Design-bidbuild is also the most common delivery method used by private developers (Pellicer et al. 2014). The reason stems from the fact that the Spanish Building Act 38/1999 shields the architect and prevents the implementation of other delivery methods (Pellicer and Victory 2006). In addition, in Spain, integrated project delivery is virtually unknown in the industry, whereas construction management at risk is seldom used (and only by industrial or commercial 
171 developers). Design-build was used in the past (staring in the 1970s) but abandoned twenty

172 years ago maybe because of its misuse by some public agencies (Pellicer et al. 2014). Due to the

173 fact that design-bid-build is the most prevalent delivery method in Spain, this research cannot

174 directly explore project delivery methods as a means of integration in the Spanish design and

175 construction industry. However, the characteristics of integration in project delivery methods,

176 such as early involvement of key construction team members in design, can be studied to see if

177 they lead to success. The effects of procurement and contracting methods on team integration

178 and success can also be studied.

179

There are five primary procurement methods that can effect integration: low bid, onestage best-value, two-stage best-value, pre-qualified negotiation, and sole source negotiation. Low bid procurement seeks competitive pricing through an open bidding process that awards a project to the lowest responsible bidder (El Wardani et al. 2006). Best-value procurements consider factors in addition to price, therefore requiring a request for proposal (RFP) from the owner and a proposal of technical and/or qualification from the constructor (Molenaar and Johnson 2003; El Wardani et al. 2006). When the RFP process is open, this is referred to as a one-stage best-value procurement. When process includes a short-listing of proposers (most often based on qualification) this is referred as a two-stage best-value procurement. In a prequalified negotiation, the owner makes a request for qualifications (RFQ) to short-list a number of firms (short-list) and they directly negotiates with the most qualified team(s) to achieve a reasonable price (Beard et al. 2001). When the request is made to only one company, it becomes a sole source negotiation (El Wardani et al. 2006). The type of procurement method can impact integration. Low bid procurement does not typically facilitate integration between the owner, designer and constructor. One and two-stage best-value procurements provide

194 more opportunity for integration as more factors besides price are added to the 
217 can be explained.

\section{Input Variables}

provides the highest opportunity to introduce team integration.

On the topic of the procurement procedures, open bid and one-stage request of proposals (RFP) are mostly applied in Spanish public contracting (de la Cruz et al. 2006). Open bid takes into consideration the price, while the one-stage RFP is focused on the best value, considering factors such as technical proposal, schedule, team experience, and quality and safety control procedures (Pellicer et al. 2014). For one-stage RFP, the price is weighted $50 \%$ or more in public contracts due to European regulations (European Commission 2004). The twostage RFP is occasionally employed by public developers (de la Cruz et al. 2006); however, it is used by private owners (Pellicer and Victory 2006). For two-stage RFP, the technical proposals are delivered first and pre-qualified bidders are short-listed; later, these qualified bidders deliver the economic offer (Molenaar et al. 1999). Private owners from time to time apply other strategies such as the qualifications-based or the sole source (Pellicer et al. 2014).

Finally, the literature review provides us with definitions for input variables. Input variables refers to factors such as type of building, gross floor area of the project, number of floors above and below ground level, complexity, percentage of prefabrication, and so on. These characteristics vary a lot from study to study. The studies have ranged in size from just a few to more than 100 as seen in Table 1. Generally, these studies establish them a priori, determining the focus of the research: private or public, vertical or horizontal, minimum or maximum area, 
As stated in the Introduction, the goal of this study is to explore how integration affects performance in the Spanish multi-family housing sector. For this purpose, the unit of analysis is the building project. The research is carried out in the phases shown in Figure 1 . In the first phase, the representatives of the owner and the constructor of 31 building projects were surveyed face-to-face in order to clarify any doubts on the questionnaire (structured interviews); most of the questions addressed owners, and only some of the questions targeted contractors (i.e., either to check the quantitative data or to get a more precise response on some topics). The questions were designed to capture the degree of integration in Spanish residential building projects.

After collecting the data, the research team aimed to compare highly integrated projects with less integrated ones. However, the variables included in the questionnaire were not mutually exclusive, which made it difficult to cluster projects based on their level of integration. For example, "timeliness of communication" and "team chemistry" can be correlated, which makes it difficult to give equal weight to all questions. Therefore, the research team needed to transform variables in such a way as to remove multicollinearity among variables. One of the most effective techniques for reducing multicollinearity among variables in a multivariate dataset is principal component analysis (PCA), which reduces the

237 dimensionality of a data set consisting of a large number of interrelated variables while retaining as much of the variation present in the data set as possible (Hair et al. 2009; Field 2013). A principal component analysis was performed on these 31 projects to determine how the variables relating to project integration interacted and to determine which projects would be best for in-depth case studies. Eight of the best and worst performing projects were selected performance. 


\section{Project Questionnaire and Data Collection}

247 The project questionnaire was written to comprehensively capture the input, decision and output variables that might apply to the research. The outcome variables were potential measures for cost, schedule and quality performance. The input variables in the project questionnaire were chosen to describe the physical and contextual aspects of the project. The input variables included items such as foundation type, square footage of project, number of floors and other physical items that describe the project. The decision variables included those that the owner could influence when defining the project. The team selected 16 potential decisions variables from the literature on project integration and project success. These variables included direct owner decisions and team behaviors that the owner could influence with their decisions. Examples of these decision variables include the owner's type of relationship with the project team, team's prior experience as a unit, project team chemistry, timeliness of owner decisions, owner's ability to make a decision, involvement of end users, colocation, formal vs. informal communication, compromise on project issues, timeliness of communication, contingency approach, and commitment to the project goals. The questionnaire survey was organized in the following sections to provide a logical flow in the interviews: project characterization, project costs, project schedule, project quality, project safety, sustainability, procurement, payment provisions, team characteristics, team behavior, process and technology, project success, and lesson learned. There were several questions on the questionnaire that required using a rating scale; some authors have suggested than using even number for response categories can lead to indecisive data, suggesting even numbers for response categories (Busch 1993; Cohen et al. 2011; Reid 1990). Considering these previous 
explanation of the steps carried out to design this questionnaire survey can be found in Esmaeili et al. (2013) and Pellicer et al. (2014).

This questionnaire was validated in two manners. First, the questionnaire was given to 10 experts with more than 15 years of experience in the Spanish building residential sub-sector. Respondents were asked for feedback on completeness and clarity of the questionnaire. Second, pilot interviews were conducted with one owner and one contractor to ensure that the questions were properly understood. The validation resulted in minor changes to the questionnaire.

A broad sample of owners and contractors was considered to gather the data; they were chosen by convenience through professional associations. The research team decided to guarantee the maximum reliability of the responses in two ways: (1) the questionnaire was administered face-to-face as a structured interview so any doubts could be clarified by the interviewer in real time; and (2) for every project there was a pair of respondents, representatives of the owner and contractor. Therefore, two interviews were done for each project, even though not the same questions were asked to owner and contractor, as explained next. If there were inconsistencies in the answers for the objective data, the research team went back to check with every interviewee; regarding the subjective data, a protocol was followed and, depending on the question, the value from one of the respondents (for nominal variables) or the average value (for ordinal variables) was considered as the one representative of the project.

The process to get in touch with the respondents started with a telephone call explaining the basics of the research and inquiring about the potential respondent's willingness to participate. Then, the research team sent an email asking for the hard data of the project. Due to the fact that two respondents per project were needed, and considering the length of the questionnaire as well as the current crisis in the Spanish construction industry, only 35 
projects were gathered; all of them were finished after 2005. However, four of them were discarded because of the incompleteness of the responses (two), inconsistency of the responses (one), or the outlying characteristics of the building project (one); the latter was an unusually tall building (43 floors) with a special design and location. Therefore, the final sample was comprised of 31 projects (comprising a total of 62 structured interviews, two per project). All the respondents were project managers working for private developers (owners) or construction companies (contractors) with, at least, 10 years of experience. The average duration of the face-to-face structured interviews was approximately two hours.

\section{Descriptive Statistics}

Data were analyzed using IBM SPSS Statistics (version 16.0). First, descriptive statistics of the variables were developed to provide an understanding for the context of the buildings being studied. The projects had a wide range of size, as measured by square footage and cost, as well as a wide range of duration. Cost data was updated to March 2015, considering economic inflation. Note that duration was inclusive of both design and construction. Project complexity was measured on a six-point Likert scale (1=low and $6=$ high). The median response was a 3 and the complexity level of the projects was quite well distributed. Table 2 provides the summarylevel descriptive statistics for the study sample.

<Insert Table 2 here>

Tables 3 and 4 provide example decision variables. These tables do not include all of the variables that were explored; rather, the tables introduce the variables that were found to be related indicators of integration and success in the PCA that will be discussed later in this subsection. These variables served to aid in case studies selection, which will be discussed in the next sub-section.

As previously stated, the Spanish design and construction industry relies almost 
exclusively on design-bid-build project delivery. Constructors and specialty contractors normally enter late, if not at the very end, of the design process. These facts constrained the ability to study integration through delivery methods. Related to the project delivery method, however, is the fact that some developers maintain in-house construction services, thereby acting as integrated developer-builders. While these organizations are not true design-builders because they outsource design services, they demonstrate more integration than those developers who outsource both design and construction. As seen in Table 3, the projects had a good distribution of $58 \%$ non-integrated (outsourced construction) and $42 \%$ integrated (in-house construction) developers.

Table 3 also provides a description of the important procurement differences that were discovered. Although design-bid-build is the primary delivery method, Spanish developers have multiple options in procuring designers and constructors. Rarely is price the only selection factor. The study population used $61 \%$ two-stage best-value procurement and $39 \%$ sole source procurement. Given this flexibility in procurement, it was found that only $26 \%$ of the procurements resulted in a first-time relationship between the developer and designer or contractor. As discussed later in the paper, these procurement characteristics were discovered to be determinants of team integration and project success.

<Insert Table 3 here>

Table 4 provides Likert scale decision variable examples. Similarly, Table 4 is not exhaustive of the decision variables that were studied, but it provides a description of the variables that were found to be related indicators of success and that were used to select the project case studies. Spanish developers can chose from a variety of project types. They can also choose builders that have experience on similar facilities. Experience was measured on similar projects on a six-point Likert scale from low to high for both the owner and the contractor. As gleaned from the literature, owners' decisions regarding their timeliness of 
communication, influence on team goal commitment and creation of an environment to enable team chemistry are among the decisions that owners control or influence and have the potential to impact project integration and success. These variables were most appropriately measured on the same Likert scale.

<Insert Table 4 here>

Table 5 summarizes the outcome variables that were chosen for the study. Although many outcome variables were identified to measure project success, some of them can be illusive or even inappropriate. In the data set, for example, schedule growth, as measured by a percentage difference between the original schedule and the final schedule, and cost growth, as measured by a percentage difference between the original cost and the final cost, were not appropriate measures of success. The reason is that the projects were speculative buildings (i.e., residences for sale). The ability of the developer to wait for a residential sale and add cost through upgrades was more important than minimizing the final time and cost against the budget; particularly during the Spanish financial crisis. From the data set, three outcome variables emerged as the best measures of project success: overall project success; overall quality; and amount of call-backs. While these variables are more qualitative, for example than cost growth, they are an appropriate measure of project success and agree with other work in measuring success relating to project integration (Konchar and Sanvido 1998; Molenaar and Songer 1998). They allow the respondents to synthesize the many facets of project success that some of the more quantitative measures cannot address. Additionally, these variables were assessed by the owner. Table 5 shows the results for overall project success, overall quality and call-backs. All three of these variables use a Likert scale, which is commonly applied in the literature. 


\section{Principal Component Analysis}

To better understand the decision variables and remove multicollinearity among variables, the team conducted a PCA to condense the dimensionality of the data space using latent, or underlying, variables (Field 2013). The PCA computes a smaller number of variables (called factors or principal components) that are a linear combination of the original variables as well as independent among them; their average is 0 and their standard deviation is 1 . The goal of the PCA is that the new factors retain as much information as possible from the original scenario based on the relationships among variables, but simplify the structure of the information (Cohen et al. 2011).

There are two types of assumptions for PCA, the conceptual and statistical (Hair et al. 2009). The conceptual assumptions require that some underlying structure should exist in the set of selected variables and that the sample should be homogenous. In this study, an in-depth literature review was conducted to identify variables that define integration in a project, and consequently, the research team assumes that there is a latent structure among these variables that needs to be detected. In addition, the sample was selected from Spanish residential building projects, which satisfies the assumption of homogeneity of data.

In conducting PCA, conceptual assumptions are much more important than statistical assumptions, and the departure from normality, homoscedasticity, and linearity in a majority of cases does not have a significant impact on the final outcome. However, before conducting the PCA analysis, one needs to test whether the data are factorable or whether there is sufficient intercorrelation between variables. To test the overall measure of intercorrelation, the research team analyzed the anti-image correlation matrix and conducted the Bartlett test of sphericity and the Kaiser-Meyer-Olkin (KMO) test, as described in Hair et al. (2009).

The study began with 16 decision variables, as stated previously, and ended up with eight variables through a step-wise PCA process. Variables with a measure of sampling 
adequacy of less than 0.5 were excluded one by one from the analysis (Field 2013; Hair et al. 2009). In order to comply with a minimum ratio of four or five responses per variable in the PCA, the research aimed to get a final set of seven or eight variables for the PCA (Martin-Martin et al. 2008; Hair et al. 2009).

The adequacy of the data set for a PCA is checked by Bartlett's spherical test $(p<0.001)$ and by the Kaiser-Meyer-Olkin (KMO) measure of sampling adequacy (KMO $=0.658$ ). Bartlett's test checks the correlation between variables, mainly when the ratio of sample size to number of variables is $5: 1$ or fewer (as it is in this case). Bartlett's spherical test showed statistical significance $(p<0.05)$ for the sample (Cohen et al. 2011). The KMO correlates pairs of variables and describes the magnitude of correlation among them. For the KMO test regarding the data, the output higher than 0.600 can be considered fair (Cohen et al. 2011). Furthermore, the determinant is 0.032 (much bigger than $10^{-5}$ ); thus, there is no multicollinearity problem either (Field 2013). For the study, the results of the tests proved that the data were suitable for a PCA according to these criteria.

The first component is chosen so it explains the maximum possible variance; whereas the second explains the maximum variance not explained by the first one, and so on. Kaiser's criterion establishes that eigenvalues greater than 1.000 should be considered principal components (Field 2013). Three principal components meet this criterion for this research; these three principal components explain $76 \%$ of the observed variability in the input data set. It is worth mentioning that each of the three principal components has a similar percentage of the cumulative variance, thus, they contribute in a similar way to project integration.

After applying a Varimax rotation (Cohen et al. 2011; Field 2013), the factor grouping shows (Table 6) the scores of the eight variables for the three principal components identified in the PCA. Load factors with values less than 0.400 have not been displayed, considering the sample size. The analysis of the factor loading matrix leads to a reduced number of components 
that can explain project integration in its various forms.

<Insert Table 6 here>

The three principal components can be interpreted in the following sense:

- Owner integration is comprised of Owner Type, Solicitation of Proposals from Contractor, and Relationship of the Owner with the Project Team. This component assesses the way the owner manages the different phases of the infrastructure lifecycle (particularly feasibility, design, procurement, and construction), establishing the functions and responsibilities of the different stakeholders.

- Team behavior is comprised of Timeliness of Communication, Team Chemistry, and Commitment of Project Team Members to the same Goals. This component displays the quality of the level of interaction among the different stakeholders.

- Project experience is comprised of Contractor Experience with similar Facilities, and Owner Experience with similar Facilities. This component measures the degree of knowledge and skills acquired by the main stakeholders (owner and contractor) because of their previous participation in similar construction projects.

\section{Case Study Selection}

With full understanding of the input, decision, and output variables, the case studies were selected for a detailed investigation. The team transformed the variables to dichotomous variables to simplify the case study selection. Integrated owner-constructor organization are show with a "+" and non-integrated organizations are shown with a "-". The decision factors are calculated using the transformations required by the principal components analysis; those whose value is above the mean are considered "+" because they have the attribute present, while below the mean, the attribute is considered "-". Overall success is a representation of the three individual success measures: overall project success; overall quality; and call-backs. When 
444 at least two of these three success variables were above the mean, the project is noted as 445 successful with a "+". Similarly, when at least two of the success variables were below the 446 mean, it was shown with a "-". Table 7 visually simplifies the case study selection. Three 447 different general configurations are apparent: (1) the best-performing projects; (2) the worst 448 performing projects; and (3) outliers that do not fit a regular pattern, such as projects 19 and 449 03.

<Insert Table 7 here>

Out of the 31 building projects, eight configurations were detected as most importation

452 to study in-depth. The criteria were not the repetition of configurations among the different 453 projects, but the singularity in accomplishing the outcome with certain combination of causal 454 conditions. The research team selected three "best" projects (two integrated and one nonintegrated from the owner point of view), three "worst" projects (one integrated and two nonintegrated from the owner point of view), and the two atypical cases that were previously mentioned. Figure 2 graphically shows the case study selection. <Insert Figure 2 here>

\section{Case Study Protocol}

A research protocol was developed for the case study design to allow for a systematic gathering 462 of data and case study validation (Yin 2009). There were two main sources of data for each case study: (1) semi-structured interviews; and (2) archival data from the project as determined by

464 the discussions. In order to encourage a productive semi-structured interview later on with the owner and contractor (if needed), detailed questions were written in each of the following areas:

(a) Design and construction functions that the owner organization possesses.

(b) Procurement process for the main contractor regarding the building project. 
(c) Explanation of overall success, overall satisfaction and call-backs, regarding the building project.

(d) Explanation of how the procurement process impacted project success in each of the areas.

(e) Explanation of how the procurement process interacted with team behavior in terms of team chemistry, shared dedication to goals and owner decision making.

(f) Benefits and challenges of having (or not having) an integrated company.

(g) Company approach to withstand the Spanish financial crisis considering the issues brought up during the interview.

478 As for any semi-structured interview, the protocol also encouraged the interviewee to raise 479 other topics that might relate to the principal research question. It was especially important in 480 the interviews to determine the reasons behind the differences between configurations; the 481 interviewer asked for specific examples and circumstances that could depict each configuration 482 better. Topics of interest raised by interviewees were asked in later interviews to determine if it 483 was a facet present in that particular project or one of general consensus. The interview was 484 recorded, transcribed and organized. Finally, memos from every interview were developed, 485 stating the concepts that were similar among projects, as well as the ones that were specific 486 (Charmaz 2006). These concepts were continuously compared with new data coming from 487 interviews and archival data from the projects, as well as from the literature review, using 488 triangulation (Yin 2009). Although a saturation of findings was frequently reached in the first 489 three to five interviews, all eight interviews were conducted to better ensure saturation (Guest 490 et al. 2006). 


\section{RESULTS AND DISCUSSION}

493 The results of this research stem from the triangulation of: (a) literature review, (b) survey analysis (structured interviews), and (c) case study investigation (archival data and semistructured interviews). The research provides a definition of integration in Spanish building residential sub-sector. The results found that higher levels of integration positively influence both team behavior and project success. The case studies also point to a better resilience of developers with integrated construction services during the Spanish financial crisis, but these results are not conclusive as the recovery is not yet complete.

While Spanish owners are not able to benefit from more integrated forms of project delivery, they have achieved higher levels of integration through three primary means: (1) including construction services as a core business practice; (2) using qualifications-based criteria when selecting key team members (general and specialty contractors); and (3) relying on previous relationships to improve integration when selecting the team. The authors believe that these three factors serve to define integration in the Spanish multi-family housing sector and that this integration has a positive influence on project success. These three factors contribute directly to positive team behaviors. This definition of integration is in agreement with other research findings, particularly those of Kumaraswamy et al. (2005) and Rahman and Kumaraswamy (2008) who indicated that similar elements move teams from classical to relational contracting. The findings support their four factors that owner's competencies, prior interactions, compatible organizational culture, and better selection of project partners encourage cooperative team-working.

As seen in Table 3, $42 \%$ of the survey population was from developers who maintain 514 construction services within their companies. This organizational structure was found to improve project success. It is the form that most resembles a design-build organization, but due 
owners procure designer services through a separate contract. Intuitively, these owners might have chosen to shed their construction services during the financial crisis. However, this was not found to be the case. In the case study interviews, these owners repeated stated the benefits of having in-house construction services. As one integrated construction developer stated from a highly successful project: "the culture of this company is to work in a team and help to achieve the common goal. This is achieved by transmitting from the top down, fostering communication and good relations." Conversely, a common theme for owners who outsource their construction is represented by the following case study statement: "we couldn't get the team to follow a single and common approach, because the goals of the owner were completely different to the goals of the constructor." While it may be difficult to maintain a larger staff during times of decreased activity due to external economic factors, it appears that successful Spanish developers are maintaining these services throughout the crisis.

The use of qualifications-based procurement factors and the selection of teams with previous experience together allow the Spanish developers to improve team integration and increase their chances of project success. Spanish law and industry practice are open to the use of best-value, qualifications based and sole source procurement (de la Cruz et al. 2006). As we discovered in the case study interviews of the best and worst performance projects, the use of non-price procurement factors with subsequent negotiation of price yielded higher levels of team integration. One statement from a developer who outsourced both design and construction, but relied on qualifications based selection of team members, was representative of the findings on the majority of projects: "we were companies with different objectives, but both sides had a common goal; we were running all in the same direction; we were all very committed and the objective was achieved." The use of qualifications-based procurement and teaming with partners with whom the developers had previous experience yielded better performance. This agrees with previous research findings in regard to non-price selection 
factors (Molenaar and Johnson 2003; Wang et al. 2013) and repetitive work with project teams (Chan et al. 2006; Nam and Tatum 1992).

Other studies have found that owners can increase the likelihood of project success through the promotion of integrated team behaviors (Baiden et el. 2006; Franz 2015). This study confirmed that trend, and specifically found that integrated team behaviors were most influenced by timeliness of owner communication, commitment to same goals and team chemistry, leading to more successful projects in the sample. In the Spanish industry, these behaviors are fostered during construction; after design and procurement. The owner obviously has direct control over the timeliness of their communications. Owners who function as integrated construction organizations have a better opportunity for timely responses. Promotion of a commitment to shared goals and an environment to foster team chemistry are influenced less directly by the owner. However, integrated teams on successful projects unanimously stated that a commitment to project. The following statements show the contrast between successful projects with integrated team behaviors and unsuccessful projects that lacked integrated team behaviors:

"The constructor was committed to the goals from the beginning of the work, the level of commitment was high because we could reach a compromise."

"During construction there was no team. It was a group of people who were forced to work together, but each with different interests."

Similar statements were found throughout the detailed case study interviews, even in the atypical case studies. As stated in one case with positive integrated behaviors, but a lack of project success: "the team had chemistry, because we have spent many years working together, but we were overconfident so the team was not committed enough to achieve the ultimate goal". While the owner's influence on commitment to goals and team chemistry may not be as direct as on the timeliness of communications, their indirect influence is important 
nonetheless. Owners create the environment to foster commitment and chemistry. Owner involvement throughout the process was found to be important in the population of Spanish multi-family housing projects.

Procuring teams with previous working relationships increased the likelihood of success on the projects that were studied, and this finding is corroborated in the literature. Case study participants pointed to previous relationships as a means of achieving integrated team behaviors and successful projects. As one case study participant from a successful project with positive team integration explained: "the team selection was done by choosing recognized professions with experience that they proved to us in previous work [...] in this project we contracted only those companies that had worked with us before and that we knew were going to be committed [to the project goals] and involved in their work." This finding is supported by numerous studies on team integration. Nam and Tatum (1992) found that long-term relationships were one of four non-contractual means of achieving integration on construction projects, promoting inter-organizational learning and building effective teams. The literature and our results show that selecting with previous experience together promotes behaviors, such as mutual goal alignment and trust, which were found to be critical in developing team integration (Chan et al. 2006; Nam and Tatum 1992).

Other research has shown that working in integrated teams with previous experience together has also been seen as a means of achieving a competitive advantage (Baiden et al. 2006), which is particularly important as the Spanish developers are emerging from the financial crisis. The case study results corroborate this finding. Additionally, this study found that it is not only experience working together, but also experience of the developer and contractor working on similar types of construction. One participant from an unsuccessful project with poor team integration is representative of multiple case studies: "the constructor had little experience in this type of building [...] with more experience, the final result would 
have been much better." While Spanish multi-family housing development companies may be compelled to move into new markets with new partners as the emerge from the financial crisis, the research shows that there is a higher chance of success if they work on teams with previous experience together on similar building types.

Similar to other studies on the impacts of integration, our study did not identify a single factor that could predict project success. Rather it appears that a combination of variables needs to be present to increase the likelihood of a successful outcome. These variables begin with how the owner organizes the team for success (i.e., integrated builder services, qualifications-based procurement, and prior experience together), and promotes success throughout the project process (i.e., timeliness of communications, shared commitment to goals, and team chemistry).

\section{CONCLUSIONS, LIMITATIONS AND FUTURE RESEARCH}

Through the literature review, survey and case studies, the authors defined integration in the Spanish building residential sub-sector and explored factors that influence team integration and project success. Even though non-traditional project delivery methods are scarcely used, owners have achieved higher levels of integration through three primary means: (1) including construction services as a core business practice; (2) using qualifications-based criteria when selecting key team members (general and specialty contractors); and (3) relying on previous relationships to improve integration when selecting the team. This study confirms previous research from other construction sectors which demonstrate that higher levels of integration can lead to better project performance (El Asmar et al. 2013; Konchar and Sanvido 1998; Pocock et al. 1996). This research extends the previous body of knowledge by providing a specific definition for integration in the Spanish residential construction sector. These findings are particularly helpful for building owners and developers in the Spanish market who are 
617 attempting to grow after the long economic crisis. The findings point to more integrated 618 building procurement strategies to improve the chance of project success. Additionally, they 619 point to a long-term integrated organizational strategy that owners and developers should

620

621

622

623

624

625

626

627

628

629

630

631

632

633

634

635

636

637

638

639

640

641

consider as their organizations grow. More generally, the results can promote discussion in Spanish public sector design and construction where the procurement and contracting laws are prohibitive of building integrated teams. Other countries have changed similar laws over the years to improve integration and project success (Latham 1994; Molenaar et al. 1999).

Readers should view these findings in light of the research limitations that were present. The most obvious limitation is the size of the study population. While eight detailed case studies of the best, worst and atypical case studies is adequate for the conclusions, a larger sample size from the survey portion of the work would allow for a statistical analysis of performance (Konchar and Sanvido, 1998; Pocock et al., 1996). Similarly, the focus on only the Spanish multi-family housing development sub-sector provides a view on one of the largest construction markets in Spain, but it limits the generalizability of the findings. It is possible that the factors for integration and project success could change in for the civil engineering or industrial sub-sectors of construction in Spain. The other notable limitation is that the study population is limited to Spain. However, the Spanish environment, with its constraints on project delivery methods that promote early contractor involvement, provides an interesting view on alternative methods to promote integration within the traditional delivery system.

Even with these limitations, the findings align well with the previously noted research on integration in other countries (El Asmar et al. 2013; Konchar and Sanvido 1998; Pocock et al. 1996; Kumaraswamy et al., 2005; Rahman and Kumaraswamy 2008). The variables studied in this research were developed from literature across different construction sectors and geographic locations. The additional contributions to the body of knowledge in defining integration in the multi-family residential sector are likely to be applicable to similar sectors 
642

643

644

645

646

647

648

649

650

651

652

653

654

655

656

657

658

659

660

661

662

663

664

665

666 outside of Spain. It is reasonable to assume that integrated builder services, qualificationsbased procurement, and prior experience together), will increase residential developers' chances of success in other countries.

The study has raised some interesting research questions for future research. Since the United States and Spain have such different project delivery environments, a more in-depth study comparing and contrasting how the two countries are achieving integration would be of interest. The industries in both countries may learn new methods from each other given their unique constraints. For future research specifically focusing on Spain, studies could explore the benefits or drawbacks from using early contractor involvement through alternative project delivery methods. The evolution of project delivery methods in the United States has improved project performance (Konchar and Sanvido 1998; Molenaar, et. al 1999; El Asmar et al. 2013). However, it is not known if these delivery methods will have the same impact in Spain with its unique legal, political and cultural constraints. Similarly, future research could focus on how the United States might benefit from the use of procurement methods that allow for more qualifications-based selection and repeat work with key owners, general contractors and specialty contractors. A final topic for future research would be to re-examine these findings at the end of the Spanish economic crisis. At the time of this research and writing of this paper, the Spanish residential building industry had not recovered to any level near the production that was witnessed prior to 2007. When the industry does recover, additional research can be conducted to determine if the results hold true and additionally to explore the other factors that lead to success of building developers in the new economy.

\section{ACKNOWLEDGEMENTS}

The authors are indebted to all the participants in this research. It was partially supported by the Spanish Government (Ministerio de Educación, Cultura y Deporte) that funded a scholarship 
667 for the first author at the University of Colorado - Boulder (reference PRX12/00066).

668

669

\section{REFERENCES}

670

Baiden, B.K., Price, A.D., and Dainty, A.R. (2006). "The extent of team integration within

671 construction projects." International Journal of Project Management, 24(1), 13-23.

672 Baiden, B. and Price, A. (2011). "The effect of integration on project delivery team 673 effectiveness." International Journal of Project Management, 29(2), 129-136.

674 Ballard, H.G., and Howell, G. (2003). "Lean project management." Building Research \& 675 Information, 31(2), 119-133.

676

Beard, J., Loulakis, E.M., and Wundram, E. (2001). Design-build: Planning through development. 677 McGraw Hill, New York.

678 Busch, M. (1993). "Using Likert scales in L2 research: A researcher comments." TESOL Quarterly, $679 \quad 27,733-726$.

680 Carballo-Cruz, F. (2011). "Causes and consequences of the Spanish economic crisis: why the 681 recovery is taken so long?" Panoeconomicus, 3, 309-328.

682 Cha, H.S., and Kim, C.K. (2011). "Quantitative approach for project performance measurement 683 684 on building construction in South Korea." KSCE Journal of Civil Engineering, 15(8), 1319-

Chan, A.P., Chan, D.W., Fan, L.C., Lam, P.T., and Yeung, J.F. (2006). “Partnering for construction 686 excellence-A reality or myth?" Building and Environment, 41(12), 1924-1933.

687 Chan, A.P.C., Ho, D.C.K., and Tam, C.M. (2001). "Design and build project success factors: 688 Multivariate analysis." Journal of Construction Engineering and Management, 127(2), 93689 100. analysis. Sage, London. 
692 CNC (2014). Informe anual del sector de la construcción 2013. Confederación Nacional de la 693 Construcción, Madrid.

694 Cohen, L., Manion, L., and Morrison, K. (2011). Research methods in education (7 ${ }^{\text {th }}$ Edition). 695 Routledge, New York. 696 de la Cruz, M.P., del Caño, A., and de la Cruz, E. (2006). "Downside risks in construction projects 697 698 developed by the civil service: the case of Spain." Journal of Construction Engineering and Management, 132(8), 844-852.

Department of Commerce (2015). U.S. Census Bureau News, October 1, 2015. Retrieved from http://census.gov/construction/c30/pdf/release.pdf (October 27).

El Asmar, M., Hanna, A., and Loh, W. (2013). "Quantifying performance for the integrated project delivery system as compared to established delivery systems." Journal of Construction Engineering and Management, 139(11), 04013012.

El Wardani, M., Messner, J.I. and Horman, M.J. (2006). "Comparing procurement methods for 705 design-build projects." Journal of Construction Engineering and Management, 132(3), 230-

European Commission (2004). "Directive 2004/18/EC on the coordination of procedures for the award of public works contracts, public supply contracts and public service contracts."

713 Field, A. (2013). Discovering statistics using SPSS (4th Edition). Sage, London.

714 Flyvbjerg, B. (2007). “Policy and planning for large-infrastructure projects: problems, causes and 715 cures." Environment and Planning B: Planning and Design, 34, 578-597. 
project performance. Ph.D. Dissertation, The Pennsylvania State University.

718 Gibson, G.E. and Whittington, D.A. (2009). "Charrettes as a method for engaging industry in best practices research." Journal of Construction Engineering and Management, 136(1), 66-

Gransberg, D.D. and Buitrago, M.E.V. (2002). “Construction project performance metrics.” AACE International Transactions, CSC.02.

Guest, G., Bunce, A., and Johnson, L. (2006). "How many interviews are enough? An experiment with data saturation and variability." Field Methods, 18(1), 59-82.

Hair, J.F., Black, W.C., Babin, B.J., Anderson, R.E. (2009). Multivariate data analysis (7 ${ }^{\text {th }}$ Edition). Pearson - Prentice Hall, Englewood Cliffs, NJ.

Ibbs, C., Kwak, Y., Ng, T.S., and Odabasi, A. (2003). "Project delivery systems and project change: quantitative analysis." Journal of Construction Engineering and Management, 129(4), 382-387.

Knutson, K., Schexnayder, C.J., Fiori, C., and Mayo, R. (2008). Construction management fundamentals. McGraw Hill, New York.

Konchar, M. and Sanvido, V. (1998). "Comparison of U.S. project delivery systems." Journal of Construction Engineering and Management, 124(6), 435-44.

Korde, T., Li, M., and Russell, A.D. (2005). "State-of-the-art review of construction performance models and factors." Construction Research Congress, San Diego, California, 1-14.

Kumaraswamy, M., Ling, F., Rahman, M., and Phng, S. (2005). "Constructing relationally integrated teams." Journal of Construction Engineering and Management, 131(10), 10761086.

Lam, E.W.M., Chan, A.P.C., and Chan, D.W.M. (2008). “Determinants of successful design-build projects." Journal of Construction Engineering and Management, 134(5), 333-341. 
742

743

744

745

746

747

748

749

750

751

752

753

754

755

756

757

758

759

760

761

762

763

764

765

766

Ling, F.Y.Y., Chan, S.L., Chong, E., and Ee, L.P. (2004). "Predicting performance of design-build and design-bid-build projects." Journal of Construction Engineering and Management, 130(1), 75-83.

Martin-Martin, Q., Cabero-Morán, M.T., Paz-Santana, M.R. (2008). Tratamiento estadístico de datos con SPSS. Paraninfo, Madrid (in Spanish).

Molenaar, K. R., Songer, A. D., and Barash, M. (1999). “Public-sector design/build evolution and performance." Journal of Management in Engineering, 15(2), 54-62.

Molenaar, K.R. and Songer, A.D. (1998). "Model for public sector design-build project selection." Journal of Construction Engineering and Management, 124(6), 467-479.

Molenaar, K.R., and Johnson, D. (2003). "Engineering the procurement process to achieve best value." Leadership and Management in Engineering, 3(3), 137-141.

Molenaar, K.R., Songer, A.D., and Barash, M. (1999). "Public sector design-build evolution and performance." Journal of Management in Engineering, 9(2), 54-62.

Mollaoglu-Korkmaz, S., Swarup, L., and Riley, D. (2011). “Delivering sustainable, highperformance buildings: Influence of project delivery methods on integration and project outcomes." Journal of Management in Engineering, 29(1), 71-78.

Moon, H., Cho, K., Hong, T., and Hyun, C. (2011). "Selection model for delivery methods for multifamily-housing construction projects." Journal of Management in Engineering, 27(2), 106-115.

Nam, C.H., and C.B. Tatum (1992). "Non-contractual methods of integration on construction projects." Journal of Construction Engineering and Management, 118(2), 385-398.

Oviedo-Haito, R.J., Jiménez, J., Cardoso, F.F., and Pellicer, E. (2014). "Survival factors for subcontractors in economic downturns." Journal of Construction Engineering and Management, 140(3), 04013056.

Pellicer, E., and Victory, R. (2006). "Implementation of project management principles in 
Spanish residential developments." International Journal of Strategic Property Management, 10, 233-248.

769

770

771

772

773

774

775

776

777

778

779

780

781

782

783

784

785

786

787

788

789

790

791

792

Pellicer, E., Sanz, A, Esmaeili, B., Molenaar, K. (2014). “Collaborative behavior in the Spanish building industry: a preliminary analysis of the dataset." $18^{\text {th }}$ International Congress on Project Management and Engineering, Alcañiz (Spain), 789-798.

Pocock, J.B., Hyun, C.T., and Liu, L.Y. (1996). "Relationship between project interaction and performance indicators." Journal of Construction Engineering and Management, 122(2), 165-176.

Rahman, M., and Kumaraswamy, M. (2008). "Relational contracting and teambuilding: assessing potential contractual and noncontractual incentives." Journal of Management in Engineering, 24(1), 48-63.

Reid, J. (1990). "The dirty laundry of ESL survey research." TESOL Quarterly, 24, 323-338.

SEOPAN (2014). Informe económico 2013. ANCOP, Madrid (in Spanish).

Songer, A.D., and Molenaar, K.R. (1997). “Appropriate project characteristics for public sector design-build projects," Journal of Construction Engineering and Management, 123(1), 3440.

Swarup, L., Korkmaz, S., and Riley D. (2011). "Project delivery metrics for sustainable, high performance buildings." Journal of Construction Engineering and Management, 137(12), 1043-1051.

Wang, W.C., Yu, W., Yang, I.T., Lin, C.C., Lee, M.T., and Cheng, Y.Y. (2013). “Applying the AHP to support the best-value contractor selection - lessons learned from two case studies in Taiwan." Journal of Civil Engineering and Management, 19(1), 24-36.

Winch, G. M. (2010). Managing construction projects. John Wiley \& Sons, London.

Yin, R.K. (2009). Case study research: Design and methods. Sage, Thousand Oaks (California). 
Previous Studies

Pocock et al. (1996)

Songer and Molenaar (1997)

Molenaar and Songer (1998)

Konchar and Sanvido (1998)

Chan et al. (2001)

Gransberg and Buitrago (2002)

Ibbs et al. (2003)

Ling et al. (2004)

Korde et al. (2005)

Lam et al. (2008)

Korkmarz et al. (2010)

Swarup et al. (2011)

Cha and Kim (2011)

Mollaoglu-Korkmaz et al. (2013)

Moon et al. (2011)

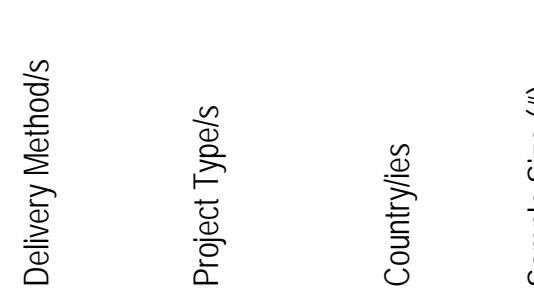

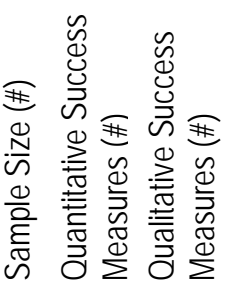

$\begin{array}{llllll}\text { All } & \text { Military } & \text { USA } & 25 & 3 & 0 \\ \text { DB } & \text { Public } & \text { USA } & 88 & 2 & 4\end{array}$

$\begin{array}{llllll}\text { DB } & \text { Public } & \text { USA } & 122 & 2 & 3\end{array}$

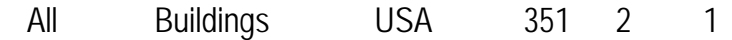

$\begin{array}{lllll}\text { DB } & \text { Public Hong Kong } & 53 & 2 & 2\end{array}$

$\begin{array}{lllll}\text { All All } & \text { USA } & \text { NA } & 2 & 0\end{array}$

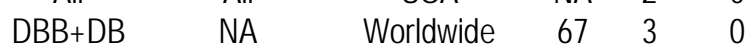

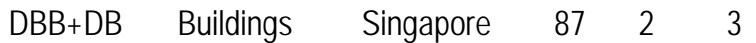

$\begin{array}{llllll}\text { All } & \text { All } & \text { Worldwide } & \text { NA } & 4 & 2\end{array}$

\begin{tabular}{|c|c|c|}
\hline & Public & $\begin{array}{lllll}\text { Public } & \text { Hong Kong } & 92 & 2 & 2\end{array}$ \\
\hline
\end{tabular}

$\begin{array}{lllll}\text { All Offices } & \text { USA } & 40 & 3 & 2\end{array}$

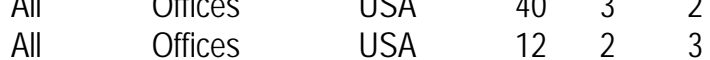

All Buildings South Korea $\begin{array}{llll}22 & 4 & 2\end{array}$

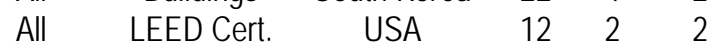

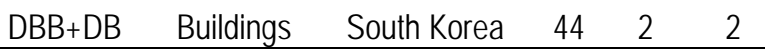

794

795 
Table 2. Examples of Input Variables

\begin{tabular}{lrrrr}
\hline & Mean & Minimum & Maximum & $\begin{array}{r}\text { Standard } \\
\text { Deviation }\end{array}$ \\
\hline Building size (sq. foot) & 96,875 & 5,166 & 318,482 & 72,095 \\
Total Cost (thousands of US\$) & 8,292 & 458 & 28,456 & 6,740 \\
Total design \& construction duration (months) & 40 & 27 & 64 & 10.3 \\
Level of Complexity (1=Low to 6=High) & 3 & 1 & 6 & 1.4 \\
\hline
\end{tabular}

797

798 
799 Table 3. Categorical Decision Variables Examples

\begin{tabular}{lcc}
\hline & Non-Integrated & Integrated \\
\hline Owner Type & $58 \%$ & $42 \%$ \\
& $2-S t a g e$ RFP & Sole Source \\
Solicitation of Proposals from Contractor & $61 \%$ & $39 \%$ \\
& & Repeat \\
Relationship of the Owner with Contractor & $26 \%$ & $74 \%$ \\
\hline
\end{tabular}

800

801 
Table 4. Likert Scale Decision Variable Examples

\begin{tabular}{lccc}
\hline LIKERT QUESTIONS (1=Low, 6=High) & Mean & Median & $\begin{array}{c}\text { Standard } \\
\text { Deviation }\end{array}$ \\
\hline Owner experience with similar facilities & 4.5 & 5.0 & 1.7 \\
Contractor experience with similar facilities & 4.9 & 5.0 & 1.3 \\
Timeliness of owner communication & 4.6 & 4.5 & 0.8 \\
Project team member goal commitment & 4.9 & 5.0 & 0.8 \\
Team chemistry & 4.6 & 4.5 & 0.6 \\
\hline
\end{tabular}

803

804 
805 Table 5. Output Variables Examples

\begin{tabular}{lccc}
\hline LIKERT QUESTIONS (1=Low, 6=High) & Mean & Median & $\begin{array}{c}\text { Standard } \\
\text { Deviation }\end{array}$ \\
\hline Overall Project Success & 4.3 & 4.0 & 1.3 \\
Overall Quality & 4.8 & 5.0 & 1.1 \\
Call-backs & 2.4 & 2.0 & 1.2 \\
\hline
\end{tabular}

806

807 
Table 6: Rotated Component Matrix

\begin{tabular}{|c|c|c|c|}
\hline Variable & PC1 & PC2 & PC3 \\
\hline Owner Type & -0.917 & & \\
\hline Solicitation of Proposals from Contractor & 0.909 & & \\
\hline Relationship of the Owner with the Project Team & 0.700 & & \\
\hline Timeliness of Communication & & 0.826 & \\
\hline Team Chemistry & & 0.770 & \\
\hline Commitment of Project Team Members to the same Goals & & 0.725 & \\
\hline Contractor Experience with similar Facilities & & & 0.915 \\
\hline Owner Experience with similar Facilities & & & 0.865 \\
\hline
\end{tabular}


811 Table 7: Case Study Selection Summary

\begin{tabular}{|c|c|c|c|c|}
\hline Code & $\begin{array}{c}\text { Owner } \\
\text { Integration }\end{array}$ & $\begin{array}{c}\text { Team } \\
\text { Behavior }\end{array}$ & $\begin{array}{c}\text { Project } \\
\text { Experience }\end{array}$ & $\begin{array}{l}\text { Overall } \\
\text { Success }\end{array}$ \\
\hline $18^{\mathrm{b}}$ & + & + & + & + \\
\hline $12^{b}$ & + & + & + & + \\
\hline 22 & + & + & + & + \\
\hline 07 & + & + & - & + \\
\hline 02 & + & + & - & + \\
\hline $19^{\mathrm{a}}$ & + & + & + & - \\
\hline 11 & + & - & + & + \\
\hline 01 & + & - & + & + \\
\hline 06 & + & - & - & + \\
\hline 20 & + & - & - & + \\
\hline 13 & + & - & + & + \\
\hline 25 & + & - & + & - \\
\hline 17 & + & - & + & - \\
\hline $27^{\mathrm{a}}$ & + & - & - & - \\
\hline $24^{a}$ & - & + & + & + \\
\hline 10 & - & + & + & + \\
\hline 09 & - & + & + & + \\
\hline 08 & - & + & + & + \\
\hline 15 & - & - & + & + \\
\hline 04 & - & - & + & + \\
\hline $03^{\mathrm{a}}$ & - & - & + & + \\
\hline 23 & - & + & + & - \\
\hline 21 & - & + & + & - \\
\hline 16 & - & + & - & - \\
\hline 30 & - & + & - & - \\
\hline 28 & - & + & - & - \\
\hline 31 & - & - & + & - \\
\hline 29 & - & - & + & - \\
\hline 05 & - & - & - & - \\
\hline $26^{w}$ & - & - & - & - \\
\hline $14^{w}$ & - & - & - & - \\
\hline
\end{tabular}

$812 \quad$ Note: (a) Atypical Cases; (b) Best Projects; and (w) Worst Projects

813

814 


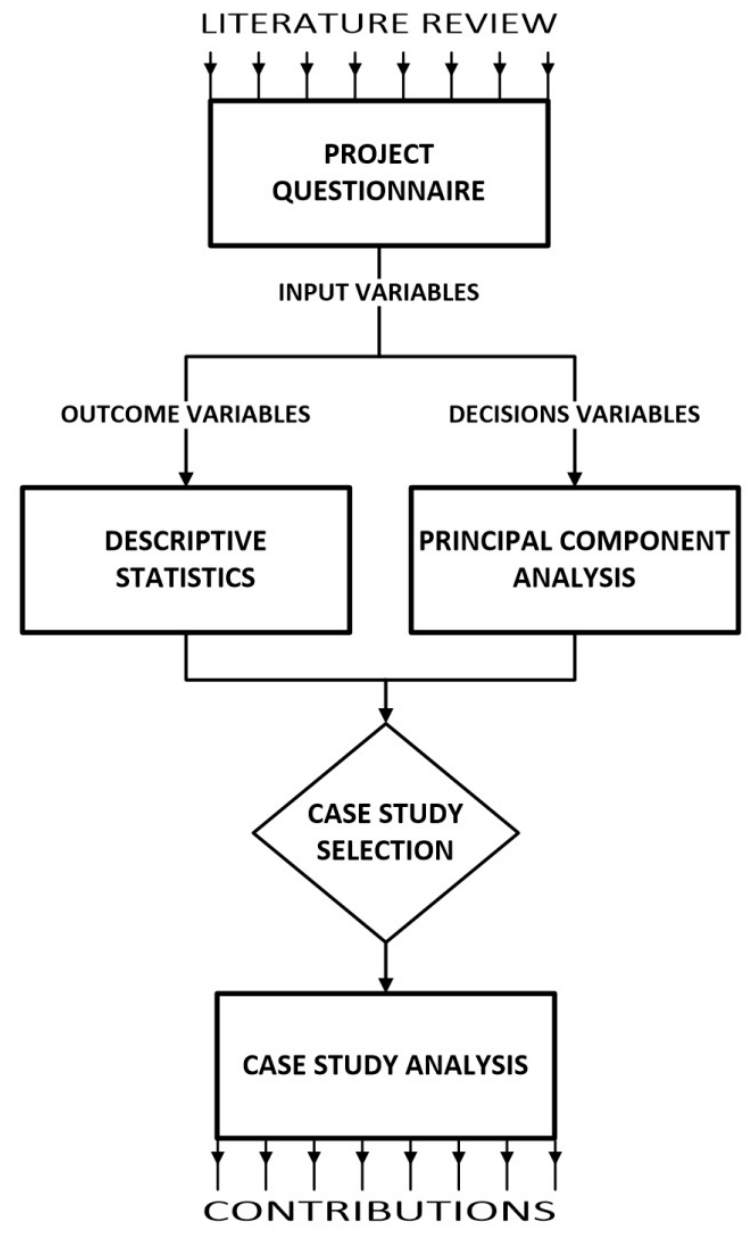

Figure 1. Research Method 


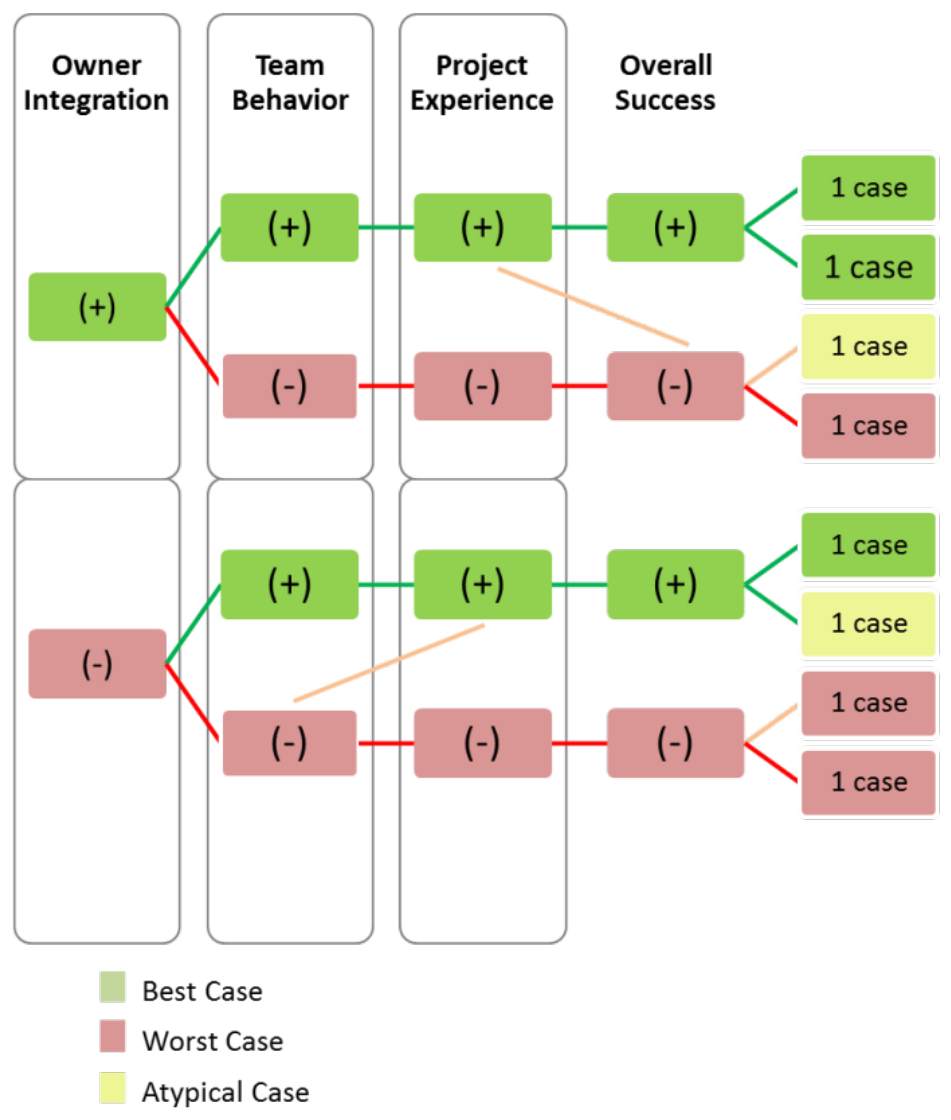

821

Figure 2: Case Study Selection

822 